\title{
Epigenetic hypomethylation and upregulation of NLRC4 and NLRP12 in Kawasaki disease
}

\author{
Ying-Hsien Huang ${ }^{1,2,3}$, Mao-Hung Lo ${ }^{1,2}$, Xin-Yuan Cai, ${ }^{1,2}$ and Ho-Chang Kuo ${ }^{1,2}$ \\ ${ }^{1}$ Department of Pediatrics, Kaohsiung Chang Gung Memorial Hospital and Chang Gung University College of Medicine, \\ Kaohsiung, Taiwan \\ ${ }^{2}$ Kawasaki Disease Center, Kaohsiung Chang Gung Memorial Hospital, Kaohsiung, Taiwan \\ ${ }^{3}$ Department of Pediatrics, Chiayi Chang Gung Memorial Hospital, Puzih-City, Taiwan \\ Correspondence to: Ho-Chang Kuo, email: erickuo48@yahoo.com.tw, dr.hckuo@gmail.com \\ Keywords: NLRC4; NLRP12; Kawasaki disease
}

Received: November 30, $2017 \quad$ Accepted: March 06, $2018 \quad$ Published: April 10, 2018

Copyright: Huang et al. This is an open-access article distributed under the terms of the Creative Commons Attribution License 3.0 (CC BY 3.0), which permits unrestricted use, distribution, and reproduction in any medium, provided the original author and source are credited.

\section{ABSTRACT}

INTRODUCTION: Kawasaki disease (KD) is a type of childhood febrile systemic vasculitis. Inflammasomes control inflammatory signaling and are related with the development of KD. In this study, we performed a survey of transcripts and global DNA methylation levels of inflammasome sensors of NOD-like receptors (NLRs) and the downstream interleukin $1 \beta$ (IL-1 $\beta$ ).

MATERIALS AND METHODS: In this study, for the chip studies, we recruited a total of $18 \mathrm{KD}$ patients, who we analyzed before receiving intravenous immunoglobulin (IVIG) and at least 3 weeks after IVIG treatment, as well as 36 non-fever controls by Illumina HumanMethylation 450 BeadChip and Affymetrix GeneChip ${ }^{\circledR}$ Human Transcriptome Array 2.0. A separate group of 78 subjects was performed for realtime quantitative PCR validations.

RESULTS: The expressions of mRNA levels of NLRC4, NLRP12, and IL-1 $\beta$ were significantly upregulated in KD patients compared to the controls $(p<0.05)$. Once KD patients underwent IVIG treatment, these genes considerably decreased. In particular, the methylation status of the CpG sites of these genes indicated a significant opposite tendency between the KD patients and the controls. Furthermore, mRNA levels of IL-1 $\beta$ represented a positive correlation with NLRC4 $(p=0.002)$. We also observed that the mRNA levels of NLRP12 were lower in KD patients who developed coronary arterial lesions $(p<0.005)$.

CONCLUSION: This study is among the first to report epigenetic hypomethylation, increased transcripts, and the upregulation of NLRC4, NLRP12 and IL-1 $\beta$ in KD patients. Moreover, a decreased upregulation of NLRP12 was related to coronary arterial lesion formation in KD patients.

\section{INTRODUCTION}

Kawasaki disease (KD), also known as mucocutaneous lymph node syndrome or infantile periarteritis nodosa, inflames the walls of both small- and medium-sized blood vessels (vasculitis), particularly coronary arteries, throughout the body. In general, KD is found in children under the age of 5 years old [1]. KD's most serious cardiovascular complications are caused by coronary artery lesions (CALs) and include coronary artery fistula formations [2], arterial remodeling, and coronary artery aneurysms (CAAs) [3]. Although this disease can be treated, nearly $20 \%$ of children who do not receive treatment suffer a CAA [2], which, in severe cases, may even cause death.

Toll-like receptors (TLRs) function as the sensor arm of the innate immune system and induce proinflammatory cytokine expressions [4]. We previously found that TLRs, particularly TLR1, 2, 4, 6, 8, and 9, were capable of 
stimulating the immunopathogenesis of KD [5]. Activating the inflammasome is the key function facilitated by the innate immune system [6]. Furthermore, growing evidence has linked inflammasomes to various autoinflammatory diseases [6], and our research team also provided evidence that $\mathrm{KD}$ is an autoimmune-like disease [7]. In recent years, researchers have strongly suggested that autoinflammatory diseases are disorders of the innate immune system, are characterized by systemic inflammation often caused by inflammasomes, and are free from infection and autoreactive antibodies or antigen-specific $\mathrm{T}$ cells [8]. NOD-like receptors (NLRs) are intracellular sensors of exogenous pathogens and endogenous damage-associated molecular pattern [9]. Once inflammasomes are activated by NLRs, the activation of caspase- 1 is activate to control the expression of such inflammatory cytokines as interleukin $1 \beta$ (IL-1 $\beta$ ) and IL-18 [10]. Furthermore, several clinical and experimental animal models have strongly implicated the function of IL-1 $\beta$ in KD [11-14].

Epigenetics indicates the DNA methylation and acetylation pattern of the genome and subsequently results in changes in the chromatin structure [15]. Previously, we found in another study that treatment with IVIG drastically altered methylation patterns in KD patients [5, 16, 17]. KD patients showed considerably increased mRNA expressions in TLRs and hypomethylation at the gene promoters of TLRs [5], and IVIG treatment can restore the methylation level of TLRs and decrease their mRNA expression [5]. However, no studies have yet surveyed the global gene expressions and methylation profiles in the NLRs of KD patients. Therefore, we aimed to comprehensively examine the mRNA expressions of these genes and analyze methylation level changes in two different stages of KD patients, as well as in control subjects.

\section{RESULTS}

\section{Differential expression of NLRC4 and NLRP12 mRNA levels in KD patients and controls and changes following IVIG treatment}

To investigate the transcript expressions of NODlike receptors (NOD1, 2, NLRC 3-5, and NLRP 1-14) [18], we used Affymetrix GeneChip ${ }^{\circledR}$ Human Transcriptome Array 2.0 to identify their expression levels. As shown in Table 1, KD patients demonstrated differential expression of NOD-like receptors when compared to both the healthy and febrile control subjects. The mRNA levels of NLRC4 and NLRP12 were significantly higher in KD patients than in the healthy control and febrile control groups. These NLRC4 and NLRP12 values significantly decreased, while NOD-1 significantly increased in KD patients after receiving IVIG treatment (Table 1). However, we found no remarkable differences in the remaining NLRCs and NLRPs among the groups or in the KD patients after undergoing IVIG treatment.

\section{Significantly altered CpG sites on NOD-like receptors between KD patients and controls}

We adopted Illumina HumanMethylation450 BeadChip (Illumina) to evaluate $\mathrm{CpG}$ site methylation patterns on NLRCs and NLRPs between KD patients and both febrile and healthy control subjects (Supplementary Table 1). We found that the NLRC and NLRP methylation levels varied considerably in patients in the acute stage of KD compared to the healthy and febrile controls (Table 2). Furthermore, methylation levels were generally significantly lower in acute-stage KD patients compared to the healthy and febrile controls (Supplementary Table $1)$. Decreased methylation causes greater gene expression [16], so we focused on the relationship between DNA methylation patterns and gene expressions. Figure 1 shows that both NLRC4 (a) and NLRP12 (b) demonstrate a hypomethylated status in KD patients that have not yet been treated with IVIG compared to the control subjects and the KD patients already treated with IVIG. Consequently, the mRNA expression level and DNA methylation of NLRC4 and NLRP12 have a negative correlation, which suggests that DNA methylation can repress gene expression.

\section{Upregulated transcripts with epigenetic hypomethylation of IL-1 $\beta$ among KD patients and controls and changes following IVIG treatment}

We explored whether inflammasome activation was capable of eliciting the expression of downstream proinflammatory cytokines IL-1 $\beta$. The mRNA levels of IL-1 $\beta$ were significantly elevated in KD patients compared to the healthy control and febrile control groups (Table 1). Furthermore, the mRNA expression level and DNA methylation of IL-1 $\beta$ have a negative correlation, which suggests that DNA methylation is able to repress gene expression (Figure 2).

\section{NLRC4 and NLRP12 expressions in the peripheral white blood cells (WBCs) of KD patients and controls}

We used real-time PCR to investigate the mRNA levels of NLRC4, NLRP12, and IL-1 $\beta$ in a separate cohort of $43 \mathrm{KD}$ patients and 35 febrile controls. In doing so, we found elevated NLRC4 ( $<<0.001)$ NLRP12 ( $<<0.001)$, and IL- $1 \beta$ mRNA levels $(p=0.021)$ in the WBCs of KD patients compared to those of the controls, as shown in Figure 3. These findings agree with the results obtained with Affymetrix GeneChip ${ }^{\circledR}$ Human Transcriptome Array 2.0. Furthermore, the mRNA level of IL-1 $\beta$ positively correlates with NLRC4 but not NLRP12, which suggests that NLRC4 was associated with IL-1 $\beta$ genes expression in KD patients (Figure 4). Moreover, the NLRP12 mRNA level was lower in KD patients who developed CAL than those who did not $(\mathrm{p}=0.0067)$ (Figure 5). 
Table 1: Transcripts expressions of nucleotide-binding oligomerization domain, leucine rich repeat with caspase recruitment domain (NLRCs) and with pyrin domain (NLRPs), interleukin 1 beta and interleukin-18 between Kawasaki disease patients and control subjects

\begin{tabular}{|c|c|c|c|c|c|c|c|c|}
\hline Symbol & RefSeq & Column ID & $\begin{array}{l}\text { Fold-Change } \\
\text { (KD1 vs. HC) }\end{array}$ & $\begin{array}{c}\text { p value } \\
\text { (KD1 vs. } \\
\text { HC) }\end{array}$ & $\begin{array}{l}\text { Fold-Change } \\
\text { (KD1 vs. FC) }\end{array}$ & $\begin{array}{c}\text { p value } \\
\text { (KD1 vs. } \\
\text { FC) }\end{array}$ & $\begin{array}{l}\text { Fold-Change } \\
\text { (KD3 vs. KD1) }\end{array}$ & $\begin{array}{c}\text { p value } \\
\text { (KD3 vs. } \\
\text { KD1) }\end{array}$ \\
\hline NOD1 & NM_006092 & TC07001249.hg.1 & 1.008 & 0.897 & -1.050 & 0.459 & -1.080 & 0.254 \\
\hline NOD2 & NM_022162 & TC16000442.hg.1 & 1.248 & 0.066 & 1.154 & 0.206 & -1.402 & $0.012^{*}$ \\
\hline NLRC3 & NM_178844 & TC16000820.hg.1 & -1.187 & $0.024^{*}$ & -1.136 & 0.072 & 1.174 & $0.031^{*}$ \\
\hline NLRC4 & NM_001199138 & TC02001723.hg.1 & 4.454 & $0.000^{*}$ & 2.159 & $0.015^{*}$ & -4.761 & $0.000^{*}$ \\
\hline NLRC5 & NM_032206 & TC16000482.hg.1 & 1.022 & 0.804 & 1.015 & 0.859 & -1.032 & 0.718 \\
\hline NLRP1 & NM_001033053 & TC17001059.hg.1 & -1.361 & $0.032^{*}$ & -1.122 & 0.364 & 1.338 & $0.040^{*}$ \\
\hline NLRP2 & NM_001174081 & TC19000887.hg.1 & -1.052 & 0.480 & -1.226 & $0.018^{*}$ & -1.002 & 0.973 \\
\hline NLRP3 & NM_001079821 & TC01002008.hg.1 & -1.040 & 0.750 & 1.131 & 0.325 & -1.046 & 0.715 \\
\hline NLRP4 & NM_134444 & TC19000913.hg.1 & -1.052 & 0.515 & -1.074 & 0.370 & 1.103 & 0.226 \\
\hline NLRP5 & NM_153447 & TC19000915.hg.1 & -1.016 & 0.803 & -1.036 & 0.580 & 1.067 & 0.323 \\
\hline NLRP6 & NM_138329 & TC11000007.hg.1 & 1.059 & 0.448 & 1.080 & 0.319 & 1.026 & 0.731 \\
\hline NLRP7 & NM_001127255 & TC19001853.hg.1 & 1.039 & 0.604 & -1.096 & 0.231 & 1.032 & 0.671 \\
\hline NLRP8 & NM_176811 & TC19000914.hg.1 & 1.022 & 0.668 & -1.019 & 0.715 & 1.010 & 0.844 \\
\hline NLRP9 & NM_176820 & TC19001880.hg.1 & 1.010 & 0.865 & 1.011 & 0.858 & 1.069 & 0.274 \\
\hline NLRP10 & NM_176821 & TC11001381.hg.1 & -1.026 & 0.764 & 1.015 & 0.864 & 1.070 & 0.442 \\
\hline NLRP11 & NM_145007 & TC19001881.hg.1 & -1.001 & 0.986 & -1.058 & 0.371 & 1.095 & 0.168 \\
\hline NLRP12 & NM_033297 & TC19001826.hg.1 & 1.466 & $0.000^{*}$ & 1.158 & $0.022^{*}$ & -1.496 & $0.000^{*}$ \\
\hline NLRP13 & NM_176810 & TC19001882.hg.1 & -1.019 & 0.867 & -1.004 & 0.974 & 1.192 & 0.138 \\
\hline NLRP14 & NM_176822 & TC11000143.hg.1 & -1.033 & 0.624 & -1.017 & 0.800 & 1.097 & 0.190 \\
\hline IL-1及 & NM_000576 & TC02002219.hg.1 & 1.677 & 0.066 & 2.195 & $0.012^{*}$ & -2.475 & $0.006^{*}$ \\
\hline IL-18 & NM_001562 & TC11002293.hg.1 & 1.411 & $0.012^{*}$ & 1.115 & 0.338 & -1.417 & $0.011^{*}$ \\
\hline
\end{tabular}

KD1: Kawasaki disease before IVIG treatment; KD3: Kawasaki disease > 3 weeks after IVIG treatment; FC: febrile control; HC: healthy control.

Table 2: Basal characteristics of controls and patients with Kawasaki disease (KD)

\begin{tabular}{lccc}
\hline Characteristic & $\begin{array}{c}\text { Healthy controls } \\
(\mathbf{n = 1 8})\end{array}$ & $\begin{array}{c}\text { Febrile controls } \\
(\mathbf{n = 5 3})\end{array}$ & $\begin{array}{c}\text { Patients with KD } \\
(\mathbf{n}=\mathbf{7 9})\end{array}$ \\
\hline Male gender & $50 \%$ & $57 \%$ & $68 \%$ \\
Mean (SD), age (y) & $2.8 \pm 1.5$ & $2.6 \pm 1.2$ & $1.8 \pm 1.6$ \\
Age range (y) & $1-6$ & $0-5$ & $0-9$ \\
\hline
\end{tabular}

\section{DISCUSSION}

As far as we know, our study is the first to perform a comprehensive survey of global DNA methylation levels and transcripts of inflammasome sensors of the NOD-like receptors between KD patients and control subjects. Our observations of particular interest include the epigenetic hypomethylation and upregulation of NLRC4 and NLRP12 in KD, as well as the increase of the downstream inflammatory cytokine IL-1 $\beta$ in KD patients. Furthermore,
IL-1 $\beta$ expression levels positively correlate with NLRC4, while NLRP12 was lower in KD patients who developed CAL than those who did not.

Growing evidence has suggested that cytokine profiles are associated with the pathogenesis of $\mathrm{KD}$, but the actual CALs involved are still unclear. In our previous studies, we found that KD patients demonstrated considerably increased mRNA expression in TLRs and hypomethylation at TLR gene promoters [5]. Inflammasomes are multimeric protein complexes 
a

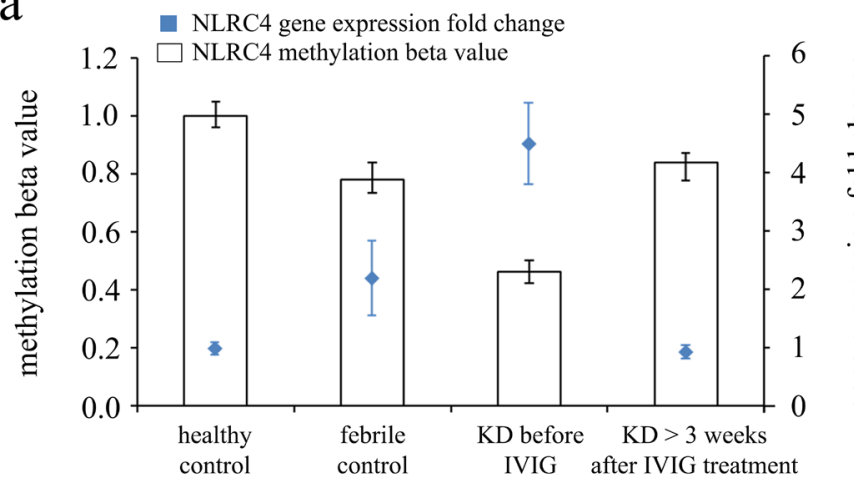

C

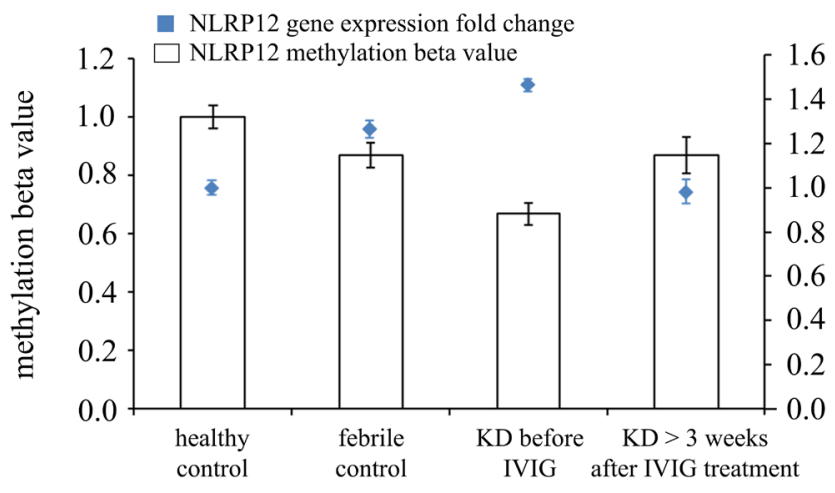

$\mathrm{b}$

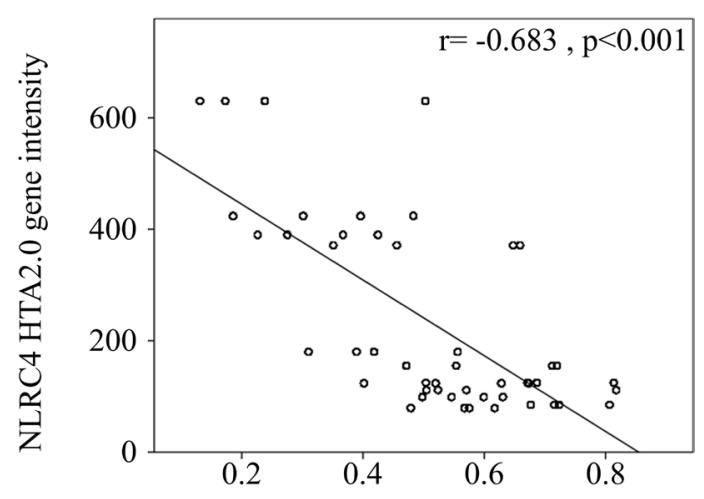

NLRC4 M450K bate value

d

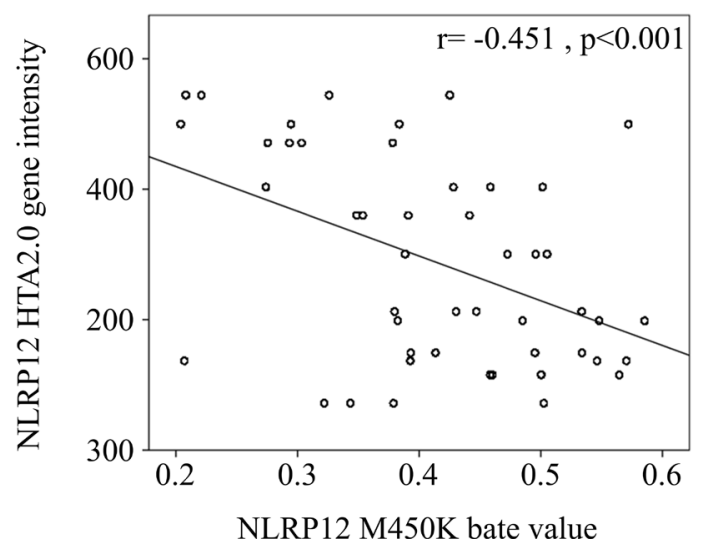

Figure 1: Integration of CpG marker methylation patterns and gene expression profiles of NLRC4 and NLRP12. The methylation patterns of the representative CpG markers ((a) cg07055315 for NLRC4 and (c) cg22337438 for NLRP12) and gene expression profiles showed negative tendencies and were observed to change in both the healthy and febrile control subjects, as well as KD patients before and after undergoing intravenous immunoglobulin treatment. The histogram and curve are presented as mean \pm standard error. (b, d) We adopted scatter plots to represent the relationship between mRNA levels and DNA methylation, which demonstrate that mRNA levels were negatively correlated with DNA methylation (Pearson's correlation coefficient approximately -0.683 and -0.451 , all $\mathrm{p}<0.001$ ).

a

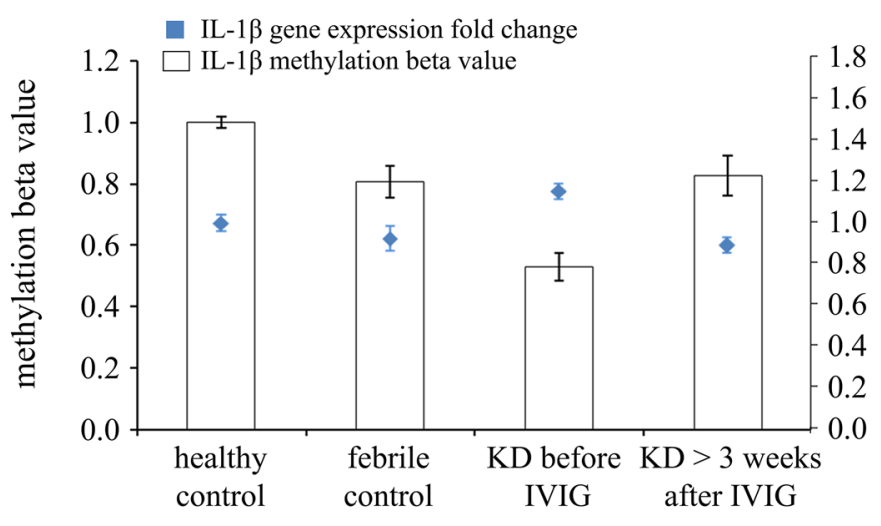

b

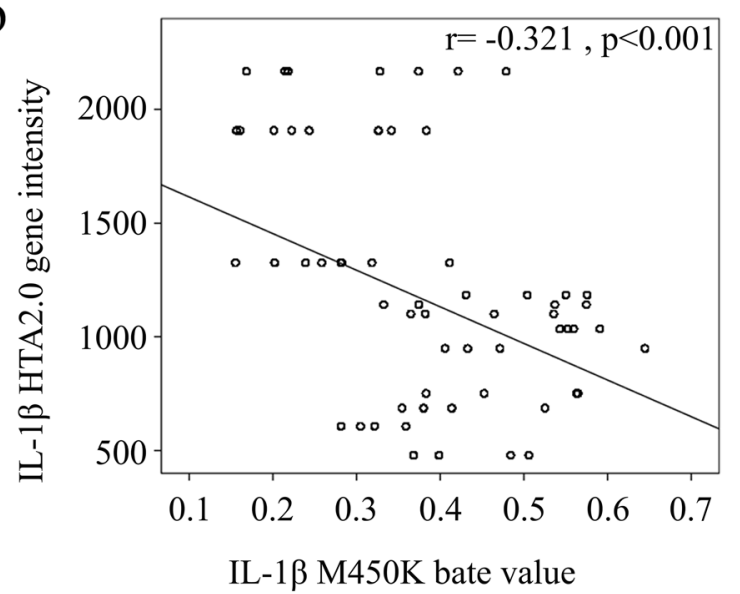

Figure 2: Integration of CpG marker methylation patterns and gene expression profiles of IL-1ß. (a) The methylation patterns of the representative $\mathrm{CpG}$ marker and gene expression profile of IL-1 $\beta$ showed negative tendencies and were observed to change in both the healthy and febrile control subjects, as well as KD patients before and after undergoing intravenous immunoglobulin treatment. The histogram and curve are presented as mean \pm standard error. (b) We adopted scatter plots to represent the relationship between mRNA levels and DNA methylation, which demonstrate that mRNA levels were negatively correlated with DNA methylation (Pearson's correlation coefficient approximately -0.321 and $\mathrm{p}<0.001$ ). 
a

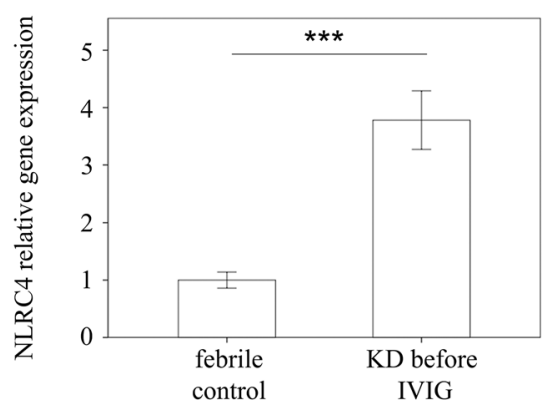

b



C

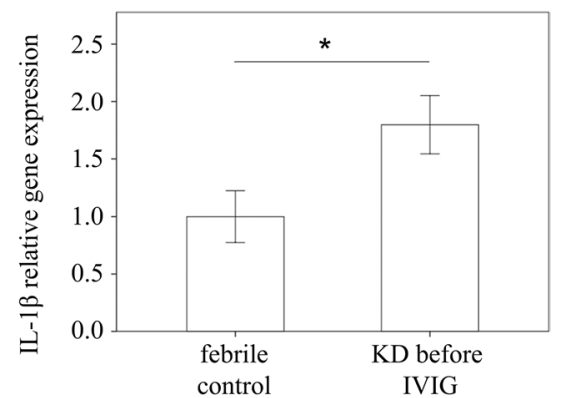

Figure 3: Analyses of (a) NLRC4, (b) NLRP12, and (c) IL-1 $\beta$ mRNA in the peripheral blood mononuclear cells of KD patients ( $\mathrm{n}=43$ ) and controls $(\mathrm{n}=35)$ using a real-time quantitative polymerase chain reaction. Data are expressed as mean \pm standard error. ${ }^{*}$ indicates $\mathrm{p}<$ 0.05 and ${ }^{* * *}$ indicates $\mathrm{p}<0.001$ between the groups.

a

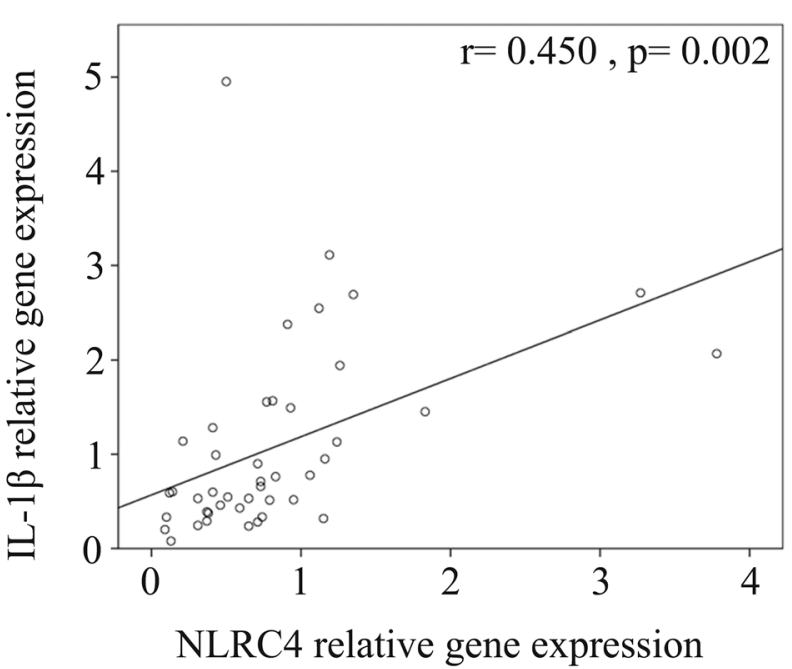

b

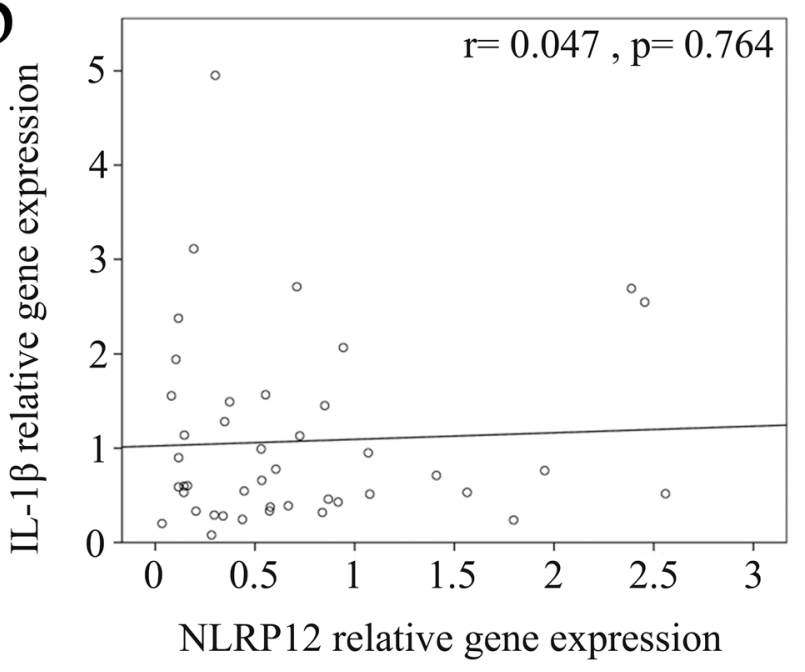

Figure 4: Correlation plots between (a) NLRC4 and (b) NLRP12 and IL-1 $\beta$ mRNA levels. The mRNA levels of IL-1 $\beta$ have a positive correlation with NLRC4 expression.

a

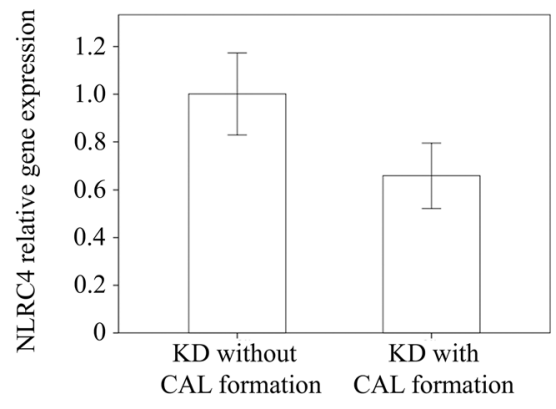

b

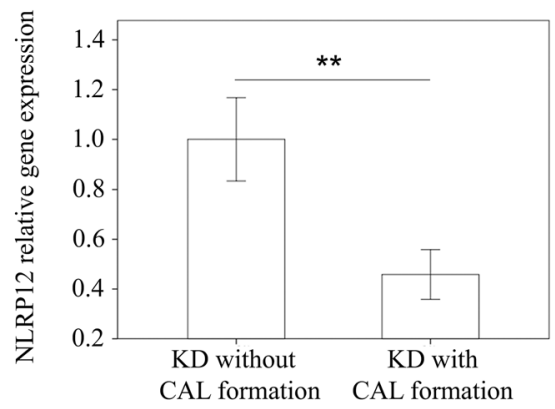

c

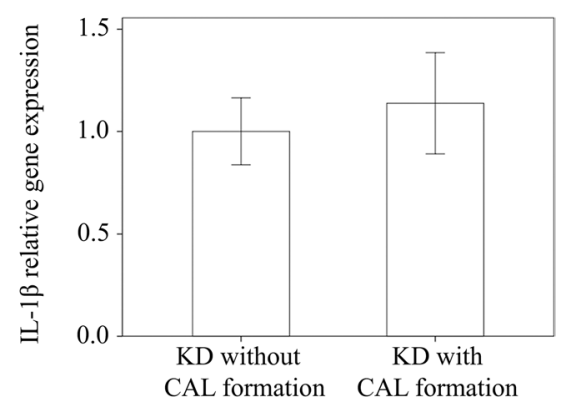

Figure 5: Comparison of (a) NLRC4 and (b) NLRP12 and (c) IL-1 $\beta$ mRNA levels in KD patients without (n=20) and with (n=23) coronary artery lesion $(\mathrm{CAL})$ before being treated with intravenous immunoglobulin. Data are presented as mean \pm standard error. ${ }^{* *}$ indicates $\mathrm{p}<0.01$ between the groups. 
Table 3: Primers list

\begin{tabular}{lccl}
\hline Gene symbol & Accession number & Hybridization & Primers (5' to 3') \\
\hline RNA18S & NR_003286.2 & forward & GTAACCCGTTGAACCCCATT \\
NLRC4 & reverse & CCATCCAATCGGTAGTAGCG \\
& NM_001199138.1 & forward & GCCTCAGGCTGCAAATAAAG \\
NLRP12 & NM_033297.2 & reverse & GGCTTCCACCATGAGAGAATAA \\
& & forward & GGCTCATGTATGTAATCCTAGCA \\
IL-1 $\beta$ & NM_000576 & reverse & CGGGTTCAAGCGATTCT \\
& & forward & CAAAGGCGGCCAGGATATAA \\
\hline
\end{tabular}

that gather in cellular cytosol after sensing innate immune system receptors and sensors in response to external infectious microbes or molecules from host proteins [6]. Activating inflammasome signaling is a key part in the pathogenesis of various cardiovascular disorders, including coronary ischemia, cardiomyopathy, and KD [19]. In this study, we have discovered significant epigenetic hypomethylation, increased transcripts, and the upregulation of the NLRC4 and NLRP12 inflammasome sensors. Our study is in line with that of Ikeda et al., who also found up-regulated NLRC4 in acute-phase KD in microarray study [20]. Not only is NLRC4 involved in sensing more than one bacterial molecule, but it also participates in a number of immune complexes [21]. Kitamura et al. identified a missense mutation in NLRC4 in patients with familial cold autoinflammatory syndrome, which promoted the formation of NLRC4-containing inflammasomes that cleave procaspase-1 and increase IL-1 $\beta$ production in order to promote the genesis of inflammatory diseases [22]. Another study identified that the somatic mutation of NLRC4 causes autoinflammatory symptoms that are compatible with neonatal-onset multisystem inflammatory disease [23].

NLRP12 is a cytoplasmic sensor that can be categorized as a negative regulator of inflammation [24] and is related to autoimmune diseases [25, 26]. Meanwhile, NLRP12 mutations cause hereditary periodic fever syndromes [27] and systemic autoinflammatory diseases [28]. Of particular note, Jin et al. observed that decreased NLRP12 in heart tissue from PM2.5 -induced mice was associated with cardiac inflammatory injury [29]. Furthermore, NLRP12 has anti-inflammatory function and down-regulation of NLRP12 is required for dextran sodium sulfate -induced release of proinflammatory cytokinesIL-1 $\beta$ [30]. Likewise, we also found that NLRP12 was lower in KD patients who developed CAL than those who did not, as well as that IL-1 $\beta$ mRNA levels do not have a positive correlation with NLRP12. Both of these findings support the theory that NLRP12 functions as a negative regulator of inflammation in $\mathrm{KD}$ patients. Based on the findings, we may apply NLRC4 and NLRP12 gene expressions and DNA methylation as KD biomarkers and develop a high-performance KD diagnosis model.

Activated macrophage produces IL-1 $\beta$, a master cytokine of systemic inflammation, which has a vital function in auto-inflammatory diseases [31, 32] and has been more recently connected to $\mathrm{KD}$ vasculitis [11-13]. Maury et al. found that the serum level of IL$1 \beta$ is significantly increased in KD patients [33]. IL-1 $\beta$ polymorphism has been associated with KD susceptibility [34] and IVIG resistance in Taiwanese children with KD [35]. Furthermore, IL-1 $\beta$ has been shown to induce myocarditis and coronary aneurysm formation in the Lactobacillus casei cell-wall extract mouse model of $\mathrm{KD}[12,13]$. In consistence with our findings in $\mathrm{KD}$ $[36,37]$, IL-1 $\beta$ pathway stimulation leads to excess production of hepcidin, which could be causative to anemia of inflammation [38]. In fact, three clinical trials of IL-1 blockade enrolling KD patients are currently being conducted in the U.S. and Europe, and these studies may be able to change the outcome of KD [39].

\section{MATERIALS AND METHODS}

\section{Patients}

In this study, we analyzed the DNA methylation levels of NLRs in $18 \mathrm{KD}$ patients, before treatment and after at least 3 weeks from receiving intravenous immunoglobulin (IVIG), and in 36 healthy (non-fever) controls by Illumina HumanMethylation 450 BeadChip and Affymetrix GeneChip ${ }^{\circledR}$ Human Transcriptome Array 2.0. Subsequently, we validated the mRNA levels of NLRs in $43 \mathrm{KD}$ patients and 35 febrile subjects by realtime quantitative PCR (Table 2). KD patients met the American Heart Association's diagnosis criteria for KD, which is characterized by extended fever for more than five days, conjunctivitis, diffuse mucosal inflammation, polymorphous skin rashes, indurative edema of the hands 
and feet associated with peeling of the finger tips in the subacute stage, and non-suppurative lymphadenopathy $[40,41]$, and treated with once dose of high-dose IVIG treatment $(2 \mathrm{~g} / \mathrm{kg})$ over $12 \mathrm{~h}$ at our hospital. The patients in the fever control group had diagnoses of acute tonsillitis, croup, acute bronchitis, bronchopneumonia, acute sinusitis, or urinary tract infection. We took peripheral blood samples from KD patients prior to undergoing IVIG treatment (pre-IVIG) and then at least three weeks after completing the IVIG treatment, as previously described in another of our studies [42]. A CAL was defined as a coronary artery with an internal diameter of at least $3 \mathrm{~mm}$ ( $4 \mathrm{~mm}$ if the patient was older than 5 years) or a segment with an internal diameter at least 1.5 times larger than that of an adjacent segment, as observed through echocardiography $[43,44]$. This study was approved by the Chang Gung Memorial Hospital's Institutional Review Board (IRB No.:101-4618A3), and we obtained written informed consent from the parents or guardians of all subjects. All of the methods that we used complied with the relevant guidelines established.

\section{Experiment design}

We first collected whole blood samples from the subjects and submitted them to WBC enrichment, as previously described in another study [16]. The enriched WBC samples were then subjected to either RNA or DNA extraction. In accordance with the manufacturer's instructions, we used an isolation kit (mirVana ${ }^{\mathrm{TM}}$ miRNA Isolation Kit, Catalog number: AM1560, Life Technologies, Carlsbad, CA) to isolate the total RNA and then calculated both the quality (RIN value) and quantity of the RNA samples using Bioanalyzer (ABI) and Qubit (Thermo). All RNA samples passed the criterion of RIN $\geqq 7$. We isolated the DNA samples and treated them with bisulfite as previously described in another study [45].

\section{Gene expression profiling with microarray}

For strong, unbiased results, we created pooled RNA libraries by evenly pooling six RNA samples, resulting in three pooled healthy control, three fever control, three pre-IVIG, and three post-IVIG libraries. We performed microarray assay on the pooled RNA samples in order to establish the gene expression profiles and then further performed profiling with GeneChip ${ }^{\circledR}$ Human Transcriptome Array 2.0 (HTA 2.0, Affymetrix, Santa Clara). We used the WT PLUS Reagent kit to prepare the RNA samples and carry out hybridization on the HTA 2.0 microarray chips. Following the Affymetrix instruction manual, we subjected the HTA 2.0 chips' raw data to quality control examination, as previously described in another study [5].

\section{DNA methylation profiling with Illumina M450K BeadChip}

We adopted Illumina HumanMethylation450 (M450K) BeadChip to perform genome-wide screening of DNA methylation patterns. The M450K BeadChip program was created to detect methylation patterns of approximately 450,000 $\mathrm{CpG}$ markers and thus spans the entire human genome. More information about M450 BeadChip can be found at the following website: http://support.illumina.com/array/array_kits/infinium humanmethylation450_beadchip_kit.html. For each M450K BeadChip assay, we applied $200 \mathrm{ng}$ of bisulfiteconverted genomic DNA pursuant to the manufacturer's instructions [16]. Then, we calculated the methylation percentage of cytosine for each $\mathrm{CpG}$ marker in each sample, which we referred to as the $\beta$ value.

\section{RNA isolation and real-time quantitative RT-PCR}

To quantify the mRNA levels of NLRC4, NLRP12, and IL-1 $\beta$, we used the LightCycler ${ }^{\circledR} 480$ Real-Time PCR System (Roche Molecular Systems, Inc. IN, USA) to carry out real-time quantitative PCR. We separated the total mRNA from the WBC using an isolation kit (mirVana $^{\mathrm{TM}}$ miRNA Isolation Kit, Catalog number: AM1560, Life Technologies, Carlsbad, CA) in accordance with the manufacturer's instructions. We performed PCR using a SYBR Green PCR Master Mix containing 10 $\mu \mathrm{M}$ of specific forward and reverse primers. The relative quantification of gene expression was carried out based on the comparative threshold cycle $\left(\mathrm{C}_{\mathrm{T}}\right)$ method, which enabled us to determine the target amount as $2^{-(\Delta C \mathrm{CT} \text { target }-\Delta}$ CT calibrator) or $2^{-\triangle \Delta C T}[46]$. Primers were designed to amplify the target genes, as shown in Table 3. We performed all experiments twice to verify and validate the amplification efficiencies.

\section{Statistical analysis}

We have presented all data as mean \pm standard error. Once chips passed the quality control criteria, we evaluated them with Partek (Partek, St. Louis), which is commercial software specifically designed to analyze microarray data. Using Partek, we conducted ANOVA analysis and reported the p-values of comparisons of interest, as previously described [5]. We adopted Student's t-test or one-way ANOVA as necessary to evaluate the quantitative data and the paired sample $t$-test to evaluate any data changes before and after IVIG treatment. All statistical analyses were carried out with SPSS version 12.0 for Windows XP (SPSS, Inc., Chicago, USA), and we considered a two-sided $\mathrm{p}$-value less than 0.05 statistically significant. 


\section{CONCLUSIONS}

Insights into the mechanisms that govern inflammasome activation in KD will help medical professionals to better understand the pathogenesis of $\mathrm{KD}$. Our study is the first to observe DNA hypomethylation and increased NLRC4 and NLRP12 transcripts in KD compared to both kinds of control subjects. Furthermore, NLRC4 was correlated with the upregulation of IL- $1 \beta$, while a decreased upregulation of NLRP12 was related to CAL formation in KD patients.

\section{CONFLICTS OF INTEREST}

The authors declare no competing financial interest.

\section{FUNDING}

This study received funding from the following grants: MOST 105-2314-B-182-050-MY3 and MOST 103-2410-H-264-004 provided by the Ministry of Science and Technology of Taiwan and CMRPG8F1911, 1921, 1931, and 1941, 8E0212 and CORPG8F0012 provided by Chang Gung Memorial Hospital in Taiwan. While these institutes provided financial support, they had no influence on the manner in which we collected, analyzed, or interpreted the data or prepared this manuscript.

All of the authors hereby declare that they have no financial interests to disclose with regard to this article.

\section{REFERENCES}

1. Kawasaki T, Kosaki F, Okawa S, Shigematsu I, Yanagawa H. A new infantile acute febrile mucocutaneous lymph node syndrome (MLNS) prevailing in Japan. Pediatrics. 1974; 54:271-76.

2. Newburger JW, Takahashi M, Burns JC, Beiser AS, Chung KJ, Duffy CE, Glode MP, Mason WH, Reddy V, Sanders SP, Shulman ST, Wiggins JW, Hicks RV, et al. The treatment of Kawasaki syndrome with intravenous gamma globulin. N Engl J Med. 1986; 315:341-47.

3. Newburger JW, Takahashi M, Gerber MA, Gewitz MH, Tani LY, Burns JC, Shulman ST, Bolger AF, Ferrieri P, Baltimore RS, Wilson WR, Baddour LM, Levison ME, et al, and Committee on Rheumatic Fever, Endocarditis, and Kawasaki Disease, Council on Cardiovascular Disease in the Young, American Heart Association. Diagnosis, treatment, and long-term management of Kawasaki disease: a statement for health professionals from the Committee on Rheumatic Fever, Endocarditis, and Kawasaki Disease, Council on Cardiovascular Disease in the Young, American Heart Association. Pediatrics. 2004; 114:1708-33.

4. Brown RL, Clarke TB. The regulation of host defences to infection by the microbiota. Immunology. 2017; 150:1-6.
5. Huang YH, Li SC, Huang LH, Chen PC, Lin YY, Lin $\mathrm{CC}$, Kuo HC. Identifying genetic hypomethylation and upregulation of Toll-like receptors in Kawasaki disease. Oncotarget. 2017; 8:11249-58. https://doi.org/10.18632/ oncotarget.14497.

6. Guo H, Callaway JB, Ting JP. Inflammasomes: mechanism of action, role in disease, and therapeutics. Nat Med. 2015; 21:677-87.

7. Guo MM, Tseng WN, Ko CH, Pan HM, Hsieh KS, Kuo HC. Th17- and Treg-related cytokine and mRNA expression are associated with acute and resolving Kawasaki disease. Allergy. 2015; 70:310-18.

8. Hoffman HM, Broderick L. The role of the inflammasome in patients with autoinflammatory diseases. J Allergy Clin Immunol. 2016; 138:3-14.

9. Vajjhala PR, Ve T, Bentham A, Stacey KJ, Kobe B. The molecular mechanisms of signaling by cooperative assembly formation in innate immunity pathways. Mol Immunol. 2017; 86:23-37.

10. Martinon F, Burns K, Tschopp J. The inflammasome: a molecular platform triggering activation of inflammatory caspases and processing of proIL-beta. Mol Cell. 2002; 10:417-26.

11. Suzuki H, Uemura S, Tone S, Iizuka T, Koike M, Hirayama $\mathrm{K}$, Maeda J. Effects of immunoglobulin and gammainterferon on the production of tumour necrosis factoralpha and interleukin-1 beta by peripheral blood monocytes in the acute phase of Kawasaki disease. Eur J Pediatr. 1996; 155:291-96.

12. Lee Y, Wakita D, Dagvadorj J, Shimada K, Chen S, Huang G, Lehman TJ, Fishbein MC, Hoffman HM, Crother TR, Arditi M. IL-1 Signaling Is Critically Required in Stromal Cells in Kawasaki Disease Vasculitis Mouse Model: role of Both IL- $1 \alpha$ and IL-1 $\beta$. Arterioscler Thromb Vasc Biol. 2015; 35:2605-16.

13. Lee Y, Schulte DJ, Shimada K, Chen S, Crother TR, Chiba $\mathrm{N}$, Fishbein MC, Lehman TJ, Arditi M. Interleukin-1 $\beta$ is crucial for the induction of coronary artery inflammation in a mouse model of Kawasaki disease. Circulation. 2012; 125:1542-50.

14. Barranco C. Vasculitis syndromes: kawasaki disease is IL-1 $\beta$-mediated. Nat Rev Rheumatol. 2016; 12:693.

15. Wilson AS, Power BE, Molloy PL. DNA hypomethylation and human diseases. Biochim Biophys Acta. 2007; 1775:138-62.

16. Li SC, Chan WC, Huang YH, Guo MM, Yu HR, Huang FC, Kuo HC, Kuo HC. Major methylation alterations on the $\mathrm{CpG}$ markers of inflammatory immune associated genes after IVIG treatment in Kawasaki disease. BMC Med Genomics. 2016 (Suppl 1); 9:37.

17. Huang YH, Yang KD, Hsu YW, Lu HF, Wong HS, Yu HR, Kuo HC, Huang FC, Lo MH, Hsieh KS, Chen SF, Chang WC, Kuo HC. Correlation ofHAMPgene polymorphisms and expression with the susceptibility and length of 
hospital stays in Taiwanese children with Kawasaki disease. Oncotarget. 2017; 8:51859-68. https://doi.org/10.18632/ oncotarget. 17700 .

18. Le HT, Harton JA. Pyrin- and CARD-only Proteins as Regulators of NLR Functions. Front Immunol. 2013; 4:275.

19. Li X, Deroide N, Mallat Z. The role of the inflammasome in cardiovascular diseases. J Mol Med (Berl). 2014; 92:307-19.

20. Ikeda K, Yamaguchi K, Tanaka T, Mizuno Y, Hijikata A, Ohara O, Takada H, Kusuhara K, Hara T. Unique activation status of peripheral blood mononuclear cells at acute phase of Kawasaki disease. Clin Exp Immunol. 2010; 160:246-55.

21. Abdelaziz DH, Amr K, Amer AO. Nlrc4/Ipaf/CLAN/ CARD12: more than a flagellin sensor. Int J Biochem Cell Biol. 2010; 42:789-91.

22. Kitamura A, Sasaki Y, Abe T, Kano H, Yasutomo K. An inherited mutation in NLRC4 causes autoinflammation in human and mice. J Exp Med. 2014; 211:2385-96.

23. Kawasaki Y, Oda H, Ito J, Niwa A, Tanaka T, Hijikata A, Seki R, Nagahashi A, Osawa M, Asaka I, Watanabe A, Nishimata S, Shirai T, et al. Identification of a HighFrequency Somatic NLRC4 Mutation as a Cause of Autoinflammation by Pluripotent Cell-Based Phenotype Dissection. Arthritis Rheumatol. 2017; 69:447-59.

24. Gurung P, Kanneganti TD. NLRP12 in autoimmune diseases. Oncotarget. 2015; 6:19950-51. https://doi. org/10.18632/oncotarget.4585.

25. Lukens JR, Gurung P, Shaw PJ, Barr MJ, Zaki MH, Brown SA, Vogel P, Chi H, Kanneganti TD. The NLRP12 Sensor Negatively Regulates Autoinflammatory Disease by Modulating Interleukin-4 Production in T Cells. Immunity. 2015; 42:654-64.

26. Jéru I, Duquesnoy P, Fernandes-Alnemri T, Cochet E, Yu JW, Lackmy-Port-Lis M, Grimprel E, Landman-Parker J, Hentgen V, Marlin S, McElreavey K, Sarkisian T, Grateau G, et al. Mutations in NALP12 cause hereditary periodic fever syndromes. Proc Natl Acad Sci USA. 2008; 105:1614-19.

27. Sönmez HE, Özen S. A clinical update on inflammasomopathies. Int Immunol. 2017; 29:393-400.

28. Shen M, Tang L, Shi X, Zeng X, Yao Q. NLRP12 autoinflammatory disease: a Chinese case series and literature review. Clin Rheumatol. 2017; 36:1661-67.

29. Jin Y, Wu Z, Wang N, Duan S, Wu Y, Wang J, Wu W, Feng F. Association of EGF Receptor and NLRs signaling with Cardiac Inflammation and Fibrosis in Mice Exposed to Fine Particulate Matter. J Biochem Mol Toxicol. 2016; 30:429-37.

30. Shi F, Yang Y, Kouadir $\mathrm{M}, \mathrm{Xu} \mathrm{W}, \mathrm{Hu} \mathrm{S}$, Wang $\mathrm{T}$. Inflammasome-independent role of NLRP12 in suppressing colonic inflammation regulated by Blimp-1. Oncotarget. 2016; 7:30575-84. https://doi.org/10.18632/ oncotarget. 8872 .
31. Nhek S, Clancy R, Lee KA, Allen NM, Barrett TJ, Marcantoni E, Nwaukoni J, Rasmussen S, Rubin M, Newman JD, Buyon JP, Berger JS. Activated Platelets Induce Endothelial Cell Activation via an Interleukin-1 $\beta$ Pathway in Systemic Lupus Erythematosus. Arterioscler Thromb Vasc Biol. 2017; 37:707-16.

32. Yilmaz M, Kendirli SG, Altintas D, Bingöl G, Antmen B. Cytokine levels in serum of patients with juvenile rheumatoid arthritis. Clin Rheumatol. 2001; 20:30-35.

33. Maury CP, Salo E, Pelkonen P. Circulating interleukin-1 beta in patients with Kawasaki disease. N Engl J Med. 1988; 319:1670-71.

34. Zou D, Ahmed Mohamed E, Jiang J, Tian L, Chen J, Li Z, Yang Z. [Correlation between $-31 \mathrm{~T} / \mathrm{C}$ polymorphisms of interleukin-1 $\beta$ gene and Kawasaki disease]. Zhong Nan Da Xue Xue Bao Yi Xue Ban. 2017; 42:8-12. Correlation between -31 T/C polymorphisms of interleukin-1beta gene and Kawasaki disease.

35. Weng KP, Hsieh KS, Ho TY, Huang SH, Lai CR, Chiu YT, Huang SC, Lin CC, Hwang YT, Ger LP. IL-1B polymorphism in association with initial intravenous immunoglobulin treatment failure in Taiwanese children with Kawasaki disease. Circ J. 2010; 74:544-51.

36. Huang YH, Kuo HC, Huang FC, Yu HR, Hsieh KS, Yang YL, Sheen JM, Li SC, Kuo HC. Hepcidin-Induced Iron Deficiency Is Related to Transient Anemia and Hypoferremia in Kawasaki Disease Patients. Int J Mol Sci. 2016; 17:17.

37. Huang YH, Kuo HC. Anemia in Kawasaki Disease: Hepcidin as a Potential Biomarker. Int J Mol Sci. 2017; 18:820.

38. Kanamori Y, Murakami M, Sugiyama M, Hashimoto O, Matsui T, Funaba M. Interleukin-1 $\beta$ (IL-1 $\beta$ ) transcriptionally activates hepcidin by inducing CCAAT enhancer-binding protein $\delta(\mathrm{C} / \mathrm{EBP} \delta)$ expression in hepatocytes. J Biol Chem. 2017; 292:10275-87.

39. Dusser P, Koné-Paut I. IL-1 Inhibition May Have an Important Role in Treating Refractory Kawasaki Disease. Front Pharmacol. 2017; 8:163.

40. Newburger JW, Takahashi M, Gerber MA, Gewitz MH, Tani LY, Burns JC, Shulman ST, Bolger AF, Ferrieri P, Baltimore RS, Wilson WR, Baddour LM, Levison ME, et al, and Committee on Rheumatic Fever, Endocarditis and Kawasaki Disease, and Council on Cardiovascular Disease in the Young, and American Heart Association, and American Academy of Pediatrics. Diagnosis, treatment, and long-term management of Kawasaki disease: a statement for health professionals from the Committee on Rheumatic Fever, Endocarditis and Kawasaki Disease, Council on Cardiovascular Disease in the Young, American Heart Association. Circulation. 2004; 110:2747-71.

41. Kuo HC, Lo MH, Hsieh KS, Guo MM, Huang YH. HighDose Aspirin is Associated with Anemia and Does Not Confer Benefit to Disease Outcomes in Kawasaki Disease. PLoS One. 2015; 10:e0144603. 
42. Kuo HC, Wang CL, Yang KD, Lo MH, Hsieh KS, Li SC, Huang YH. Plasma Prostaglandin E2 Levels Correlated with the Prevention of Intravenous Immunoglobulin Resistance and Coronary Artery Lesions Formation via CD40L in Kawasaki Disease. PLoS One. 2016; 11:e0161265.

43. Kuo HC, Wang CL, Liang CD, Yu HR, Huang CF, Wang L, Hwang KP, Yang KD. Association of lower eosinophilrelated T helper 2 (Th2) cytokines with coronary artery lesions in Kawasaki disease. Pediatr Allergy Immunol. 2009; 20:266-72.

44. Kuo HC, Yang KD, Liang CD, Bong CN, Yu HR, Wang L, Wang CL. The relationship of eosinophilia to intravenous immunoglobulin treatment failure in Kawasaki disease. Pediatr Allergy Immunol. 2007; 18:354-59.

45. Kuo HC, Chang JC, Kuo HC, Yu HR, Wang CL, Lee CP, Huang LT, Yang KD. Identification of an association between genomic hypomethylation of FCGR2A and susceptibility to Kawasaki disease and intravenous immunoglobulin resistance by DNA methylation array. Arthritis Rheumatol. 2015; 67:828-36.

46. Yang YL, Wang FS, Li SC, Tiao MM, Huang YH. MicroRNA-29a Alleviates Bile Duct Ligation Exacerbation of Hepatic Fibrosis in Mice through Epigenetic Control of Methyltransferases. Int J Mol Sci. 2017; 18:192. 